\title{
Plasma levels of luteinizing hormone in intact and castrated photosensitive blackheaded buntings (Emberiza melanocephala) exposed to stimulatory and nonstimulatory photoperiods
}

\author{
V Kumar, N Jain, BP Singh, BS Kumar \\ Meerut University, Department of Zoology, Meerut 250005, India
}

(Received 3 November 1992; accepted 2 February 1993)

\begin{abstract}
Summary - Experiments were performed to investigate the effects of castration and/or photostimulation on plasma luteinizing hormone $(\mathrm{LH})$ in photosensitive blackhead buntings. Castration evoked a significant rise in plasma LH in birds held under $8 \mathrm{~h}$ light: $16 \mathrm{~h}$ darkness (8L:16D). On exposure to $18 \mathrm{~L}: 6 \mathrm{D}$ for $24 \mathrm{~d}$, both the intact birds and the castrates exhibited a significant rise in plasma $\mathrm{LH}$, although the change in LH levels in the castrates was $=8$ times greater than in the intact birds. When control birds under 8L:16D which showed no change in plasma $\mathrm{LH}$ up to $\mathrm{d} 13$ were transferred to a 36-h resonance cycle (8L:28D), plasma LH rose significantly within 4 cycles of the treatment. Furthermore, the intact buntings showed rapid increase and decrease in the plasma LH levels during a 16-wk exposure to long (16L:8D) but not to short (8L:16D) photoperiods. These results suggest that: i) the photoperiodic drive on $\mathrm{LH}$ secretion is inhibited by the testes; ii) the blackheaded bunting has a strong photoresponsive system; and iii) a circadian rhythm of photosensitivity is involved in the photoperiodic time measurement in this species.
\end{abstract}

luteinizing hormone / photostimulation / castration / bird / bunting

Résumé - Niveaux de LH plasmatique chez des bruants (Emberiza melanocephala) intacts ou castrés exposés à des photopériodes stimulantes ou non stimulantes. Des expériences ont été effectuées pour tester les effets de la castration et/ou de la photostimulation sur le niveau de LH plasmatique chez des bruants mâles. La castration entraîne une augmentation significative du niveau de LH chez les oiseaux maintenus sous un régime non stimulant; $8 \mathrm{~h}$ de lumière/16 h d'obscurité $(8 \mathrm{~L} / 6 \mathrm{~N})$. Après exposition à un régime stimulant $(18 \mathrm{~L} / 6 \mathrm{~N})$ pendant $24 \mathrm{j}$, les animaux intacts et castrés montrent une augmentation significative de la LH plasmatique, cependant l'augmentation chez les castrés est 8 fois supérieure. Des oiseaux maintenus sous le régime $8 \mathrm{~L} / 16 \mathrm{~N}$ et ne montrant aucun changement du niveau de LH pendant $13 \mathrm{j}$, présentent une augmentation significative du niveau de $\mathrm{LH}, 6 \mathrm{j}$ après transfert à un cycle de $36 \mathrm{~h}(8 \mathrm{~L} / 28 \mathrm{~N})$. En outre, les bruants intacts montrent une augmentation puis une diminution rapides du niveau de $\mathrm{LH}$ pendant une exposition de 16 semaines à une photopériode longue $(16 \mathrm{~L} / 8 \mathrm{~N})$. Ces résultats suggèrent (1) que l'entrainement photopériodique de la sécrétion de LH est inhibié par les testicules, (2) que le bruant a un système fortement photosensible et (3) qu'un rythme circadien de photosensibilité est impliqué dans la mesure du temps photopériodique dans cette espèce. 


\section{INTRODUCTION}

In seasonally breeding birds in which reproduction usually begins some time during spring, the photoperiodic stimulation results in an increase in the plasma concentration of gonadotrophins and subsequent gonadal growth. Reproductive season in most of these species ends by the development of a state of refractoriness which is marked by a sharp decline in the circulating levels of gonadotrophins and subsequent gonadal regression. The photosensitivity is gradually regained during the following autumn in response to short days (for review see Farner et al, 1983; Nicholls et al, 1988). Gonadal steroids seem to play an importat role in the photoperiodically regulated reproductive cycle of these species through negative feedback inhibition at either the hypophyseal or hypothalamic level or both (Follett, 1984). Wilson (1985) has demonstrated that the sensitivity of steroid inhibition progressively decreases during photostimulation but increases when photosensitivity is recovered. This is supported by the results showing a significant increase in plasma $\mathrm{LH}$ after removal of the gonads in photosensitive birds. However, the magnitude of this castration response depends on the photoperiodic requirement of a particular species, as well as on whether or not the individuals are chronically photosensitive (Nicholls et al, 1988; Wilson, 1990a). The somewhat surprising fact is that most of the experimental evidence pertains to the temperate seasonal breeders and almost nothing is known about those species which reproduce at high latitudes but overwinter in the tropics or those which live and reproduce in the tropics but use photoperiod to time their breeding season. This paper reports the results from such a species, the blackheaded bunting (Emberiza melanocephala) for which some information is now available regarding the role of photoperiod in gonad development cycle.

The blackheaded bunting, a sexually dimorphic emberizid finch which migrates between west Asia/east Europe and the Indian subcontinent, is a typical photoperiodic species in that the gonadal growth is initiated by the increasingly long daylengths of late spring and early summer, a response that is mimicked under laboratory conditions by exposing photosensitive birds to an artificially long day, eg 15L:9D (Tewary and Kumar, 1982). It is suggested that the photoperiodic induction by long days in buntings occurs when light extends into the photoinducible phase $(\Phi \mathrm{i})$ of an endogenous circadian rhythm of sensitivity to light (Tewary and Kumar, 1981a). These findings are based on the measurement of testes size which reflects the summation of the gametogenic changes as a function of photoperiodic effects on the hypothalamohypophyseal-gonadal $(\mathrm{h}-\mathrm{h}-\mathrm{g})$ axis over a long period of time. Here, we report changes in the levels of luteinizing hormone (LH) in plasma as a result of castration and/or photoperiodic induction in the photosensitive buntings. The specific goals of the present experiments were to: i) determine an endocrine $(\mathrm{LH})$ response of buntings under both nonstimulatory short days $(8 \mathrm{~h}$ light:16 h darkness; 8L:16D) and stimulatory long days (16L:8D or $18 \mathrm{~L}: 6 \mathrm{D})$ as well as under a stimulatory resonance photoschedule (8L:28D); and ii) assess the influence of the testes on $\mathrm{LH}$ secretion.

\section{MATERIALS AND METHODS}

Adult males were caught from the overwintering flocks at Varanasi, India $\left(25^{\circ} \mathrm{N}\right)$ in mid-February 1991 or 1992 , brought to Meerut $\left(29^{\circ} \mathrm{N}\right)$ and placed in an outdoor aviary. At Meerut, the seasonal variations in daylength occur between the shortest daylength of $11 \mathrm{~h} 05 \mathrm{~min}$ (22nd December) and the longest daylength of $14 \mathrm{~h} 57 \mathrm{~min}$ 
(23 June); this includes 24-28 min of morning and evening civil twilight periods. In the first week of March (daylength $=12.5 \mathrm{~h}$ ), they were housed in small groups $(n=6-8)$ in wire-net cages $($ size $=50 \times 35 \times 30 \mathrm{~cm}$ ), brought indoors and acclimatized to the laboratory conditions for 2 wk. At this time all the birds had small testes (testicular volume: $0.52-0.65 \mathrm{~mm}^{3}$ ), as detected by unilateral laparotomy (Tewary and Kumar, 1981 b). Two experiments were performed.

\section{Experiment 1}

Acclimated birds were placed on a short daily photoperiod (8L:16D; lights on at 06:00 h) until the beginning of the experiment; short days are nonstimulatory but maintain the phososensitivity in this species (Tewary and Kumar, 1982; unpublished data). Five groups ( $n=8$ each) of such short-day pretreated birds were employed in this experiment. On 5 June 1991, 2 groups were castrated and the other 3 groups were sham-operated, as described in an earlier publication (Tewary and Kumar, 1981b). All the birds had maintained small testes under $8 \mathrm{~L}: 16 \mathrm{D}$; the mean volume of extirpated testes was 0.51 $\pm 0.09 \mathrm{~mm}^{3}$ ). Three d later, while in $8 \mathrm{~L}: 16 \mathrm{D}$, a sample of blood was taken from each bird of both the intact and castrated groups. On the following day a group of intact birds and a group of castrates were exposed to 18L:6D (lights on at $06: 00 \mathrm{~h}$ ) for $24 \mathrm{~d}$; the remaining 2 groups of intact and a group of castrated birds were retained on 8L:16D and served as control. Of the 3 groups on short days, 1 group of intact birds and 1 group of castrates were transferred to an 8L:28D resonance cycle for $6 \mathrm{~d}$ (4 cycles) on $\mathrm{d}$ 14 , by extending the dark period of the $8 \mathrm{~L}: 16 \mathrm{D}$ schedule. This transfer to a 36-h cycle was effected to examine whether or not the 2 (2nd and 4 th) alternate 8 - $h$ light pulses of $8 \mathrm{~L}: 28 \mathrm{D}$, falling in the middle of the subjective night and thus thought to coincide with $\Phi i$, are able to induce a long day response. The third group of intact birds was maintained on short days until the end of the experiment (d 24).

Blood samples were collected between 10:00 and 11:00 $\mathrm{h}$ after $1,3,7,13,19$ and $24 \mathrm{~d}$ of long-day photostimulation. Those under $8 \mathrm{~L}: 16 \mathrm{D}$ and then exposed to 8L:28D were bled simultaneously, except on the last day when the experiment was discontinued.

\section{Experiment 2}

This experiment was performed to determine the temporal changes in $\mathrm{LH}$ secretion through a whole photoinduced cycle. In third week of March 1992, groups ( $n=11$ or 12 ) of acclimated birds were exposed to $8 \mathrm{~L}: 16 \mathrm{D}$ and $16 \mathrm{~L}: 8 \mathrm{D}$ for a period of 16 wk. Blood samples were collected between 10:00 and 11:00 $\mathrm{h}$ at the beginning and after every 1 or 2 wk of photostimulation, as indicated in figure 2.

At each time, a sample of $100-150 \mu$ l whole blood was collected from the wing vein into heparinized capillary tubes. All samples were centrifuged and the plasma supernatants were stored at $-20^{\circ} \mathrm{C}$. The $\mathrm{LH}$ concentration in plasma was measured by a micromodification of the radioimmunoassay method develop by Follett et al (1972), using duplicate plasma samples (10 $\mu \mathrm{l} /$ sample) and original chicken LH fraction IRC-2 as standard. There was a close parallelism be tween a chicken LH standard curve and a bunting plasma dilution curve. The sensitivity (ie $90 \% \mathrm{~B} / \mathrm{BO})$ of this assay was $0.10 \mathrm{ng} / \mathrm{ml}(2 \mathrm{pg} /$ tube).

All birds were provided food and water ad libitum. Artificial photostimulation in light-proof chambers provided fluorescent light at an intensity of $\approx 300$ lux at perch level. The body weight and dimensions of the left testis, as determined by the laparotomy, of intact birds in the first experiment were recorded at the beginning and end of the experiment. The testicular size was represented by the testicular volume which was estimated by the formula $4 / 3 \pi a b^{2}$, where $a$ and $b$ denote half of the long and short axes, respectively.

\section{Statistical analysis}

The data were analyzed by the analysis of variance (ANOVA) using repeated measures design, followed by Newman-Keuls test for pairwise comparison of means within the group. Comparison of means between groups was performed by Student's $t$-test. The ANOVA and Newman-Keuls test were performed using CLR (Clear Lake Research, Houston, TX, USA) ANOVA program. Two birds in the second experiment (1 bird each under 8L:16D and 16L:8D) died during the study and their data were excluded from the analysis. 


\section{RESULTS}

\section{Experiment 1}

\section{Effect of castration under short days}

Castration brought about a rapid rise in the plasma LH levels in buntings held under short days. In castrates, the mean concentration of $\mathrm{LH}$ in plasma $(2.56 \pm 0.43 \mathrm{ng} / \mathrm{ml}$; $n=16$ ) sampled $3 \mathrm{~d}$ after castration was 3-4 times greater (significantly different $P<0.001$, $t$-test) than in intact birds (0.64 $\pm 0.11 \mathrm{ng} / \mathrm{ml} ; n=16)$.

\section{Effect of long days}

In contrast to short days (8L:16D) in which birds maintained small testes (d 0 vs $24=$ $0.52 \pm 0.05$ vs $\left.0.60 \pm 0.06 \mathrm{~mm}^{3}\right)$ and normal body weight ( $\mathrm{d} 0$ vs $24=28.49 \pm 1.99$ vs $26.56 \pm 1.60 \mathrm{~g}$ ), long photoperiods (18L:6D) induced a significant increase $(P<0.01)$ in testicular size (d 0 vs $24=$ $0.55 \pm 0.05$ vs $69.15 \pm 10.28 \mathrm{~mm}^{3}$ ) and gain in body weight (d 0 vs $24=31.08 \pm$ 1.46 vs $40.76 \pm 1.52 \mathrm{~g}$ ) within $24 \mathrm{~d}$ of the treatment.

A single long day of photostimulation caused a small (mean change in $\mathrm{LH}(\Delta \mathrm{LH})$ $=1.21 \pm 0.18 \mathrm{ng} / \mathrm{ml})$ but significant rise $(P<$ 0.05 ) in plasma $\mathrm{LH}$ in intact birds (fig $1 A$ ). In castrates although the plasma LH levels rose consistently after 1 and $3 \mathrm{~d}$ in 18L:6D (mean $\Delta \mathrm{LH}=1.84 \pm 0.38$ and $3.23 \pm 0.83$ $\mathrm{ng} / \mathrm{ml}$, respectively), the first significant rise $(P<0.01)$ was found after $7 \mathrm{~d}$ in long days (fig 1A). Photostimulated increased levels of plasma $\mathrm{LH}$ in both the groups were sustained until the end of the experiment; the castrates had $\approx 8$-fold higher circulating $\mathrm{LH}$ titres than the intact birds. ANOVA of the data indicated that there was a significant $(P<0.001)$ effect of group, days of exposure and group $x$ day interaction.
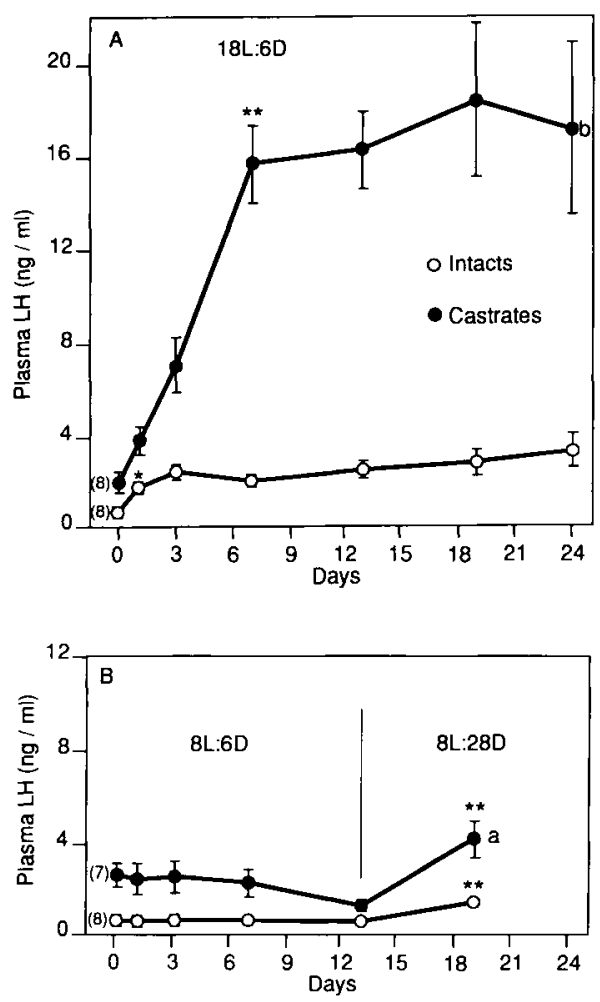

Fig 1. Plasma $\mathrm{LH}$ concentrations in buntings exposed to $18 \mathrm{~L}: 6 \mathrm{D}$ for $24 \mathrm{~d}(\mathrm{~A})$ and to $8 \mathrm{~L}: 16 \mathrm{D}$ for $13 \mathrm{~d}$ and then 8L:28D for $6 \mathrm{~d}(\mathrm{~B})$. Each circle represents the mean for a group of birds and the vertical line on these symbols indicates the SE if it extends the limit of the symbol. The figure in parentheses on the left of $d 0$ value indicates the number of birds in a treatment. The last blood sample from one of the castrated birds under $8 \mathrm{~L}: 28 \mathrm{D}$ was lost; this bird was therefore excluded from the statistical analysis. The differences between means within a group, as compared with the preceding value, are denoted by the asterisks (" $P<0.05$; ${ }^{* *} P<0.01$ ). The letters to the right of the last point symbols indicate the significance of difference $(a, P<0.01$; $b, P<0.001$ ) in means between groups (intact vs castrates), which existed throughout the treatment (except on d 13 in fig 1B), as well as the effect of days of exposure and group $x$ day interaction. 


\section{Effect of resonance photoschedule}

Buntings on short days for $13 \mathrm{~d}$ did not show any change in plasma $\mathrm{LH}$ levels. $\mathrm{A}$ significant difference $(P<0.01)$ in mean LH levels between intact and castrated birds shown throughout the experiment was no longer apparent on d 13 (fig 1B). After exposure to $8 \mathrm{~L}: 28 \mathrm{D}$, plasma $\mathrm{LH}$ levels rose significantly $(P<0.01)$ in both groups within 4 cycles of treatment. However, there was a significant difference $(P<0.01)$ in photostimulated plasma LH levels between castrates and intact birds at the end of the treatment period (fig 1B).

\section{Experiment 2}

Figure 2 describes the changes in plasma $\mathrm{LH}$ in the intact buntings during long-term exposure to short and long days. As expected, the plasma LH levels were low and remained almost unchanged in birds exposed to $8 \mathrm{~L}: 16 \mathrm{D}$. In contrast, those birds subjected to $16 \mathrm{~L}: 8 \mathrm{D}$ showed a significant $(P<0.01)$ rise in plasma $\mathrm{LH}$ after $7 \mathrm{~d}$ of long days. Plasma LH rose further $(P<$ 0.01 ) and attained peak levels after 4 wk of long days. Although photostimulated plasma $\mathrm{LH}$ levels started decreasing $(P<0.01)$ by the 6 th $w \mathrm{k}$, they remained high $(P<$ $0.02, P<0.001$ ) for the next 6 wk before reaching the non-photostimulated levels by the 12th wk of long-day exposure (fig 2). ANOVA of the data indicated a significant effect $(P<0.001)$ of group, days of exposure and group $x$ day interaction.

\section{DISCUSSION}

The post-castration elevation in plasma LH levels observed under short days suggests that there is a functional relationship between the testes and the hypothalamo-

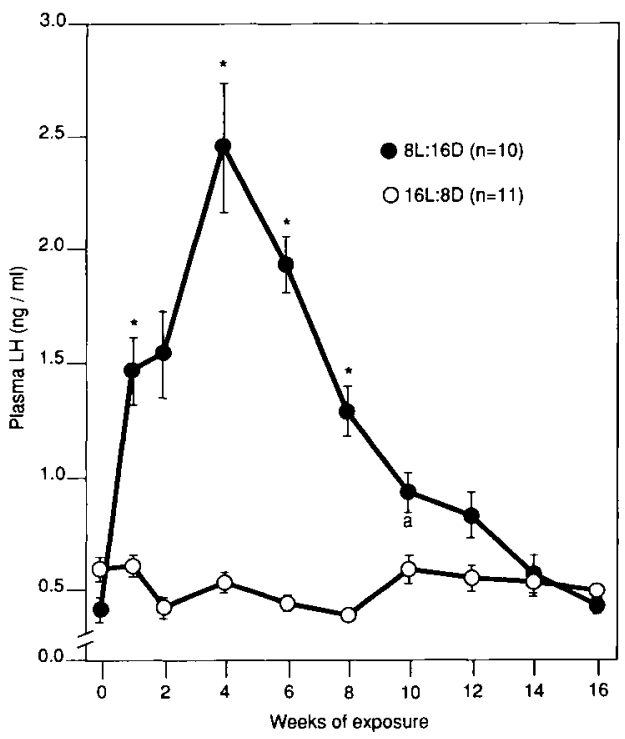

Fig 2. Plasma $\mathrm{LH}$ concentrations in intact buntings subjected to short (8L:16D) and long (16L:8D) photoperiods for a 16-wk period. Circles represent the mean and the vertical lines on them indicate SEs if they extend the limit of the symbol. The asterisk denotes the significance of difference $(P<0.01)$ as compared with the mean of the preceding observation in the same group. The letter a below the standard error bar indicates the significance of difference $(P<0.02)$ between the mean plasma LH levels of short-day and long-day groups after $10 \mathrm{wk}$ photostimulation. Note that a significant difference $(P<0.001)$ existed between the mean plasma LH levels of short-day and long-day birds from $1-8$ wk of photostimulation.

hypophysial ( $h-h)$ axis in nonphotostimulated buntings, similar to that reported in many temperate zone photoperiodic species (Wilson and Follett, 1974; Gibson et al, 1975; Davies et al, 1976; Sharp and Moss, 1977; Wingfield et al, 1980). This is consistent with the finding 
that seasonally breeding birds with sexually quiescent testes have detectable plasma androgen levels which suppress the intrinsic drive on the secretion of $\mathrm{LH}$ in plasma through their negative feedback inhibition of the $h-h$ axis (Wilson, 1985). The inhibitory effect of the testes on $\mathrm{LH}$ secretion in buntings is also evidenced by the fact that on exposure to long days the plasma $\mathrm{LH}$ in castrates rose to much higher levels than in intact birds (fig 1A).

However, all photoperiodic species do not necessarily show castration-evoked plasma LH response under short days (Wilson, 1990b). Furthermore, the castration-induced changes in plasma $\mathrm{LH}$ might differ among individuals of the same species depending on their photosensitivity. For example, castration evokes a plasma $\mathrm{LH}$ response in chronically photosensitive tree sparrows (Wilson and Follett, 1974; Wilson, 1990a) or white-crowned sparrows (Wingfield et al, 1980) but not in acutely photosensitive individuals of these species (Wilson, 1990b; Mattocks, 1985). Our results in buntings appear to be qualitatively similar to those of chronically photosensitive tree sparrows or white-crowned sparrows, although it remains to be determined whether or not castration would evoke similar plasma LH responses in acutely photosensitive buntings.

The data on body weight and testis size (experiment 1) suggest that the birds were photosensitive when subjected to the photoperiodic treatments and that the long days are required to induce gonadal growth and body fattening in buntings. This is supported by the results on longday induced plasma $\mathrm{LH}$ response in both the castrates and intact birds (fig 1A) as well as by the temporal changes in the plasma LH in intact buntings through a whole long-day induced cycle (fig 2). It may be noted that the plasma $\mathrm{LH}$ in the intact birds following long-day (16L:8D) photostimulation which showed a rapid rise remained at the relatively constant level during much of the gonadal growth phase, and subsequently declined at the onset of photorefractoriness (fig 2). A similar situation exists in other photoperiodic species exhibiting photorefractoriness (for review see Farner et al, 1983; Nicholls et al, 1988). Thus, taken together, the present results confirm our earlier finding (Tewary and Kumar, 1982) that in buntings short days are non-stimulatory whilst long days induce complete gonadal growthinvolution cycle with the development of refractoriness to the stimulatory effects of the long photoperiods. Furthermore, the plasma $L H$ response observed under long days (figs $1 \mathrm{~A}, 2$ ) indicates that buntings have a highly responsive photoneuroendocrine system which can be stimulated by even a single long day (fig $1 \mathrm{~A}$ ). This is qualitatively similar to the photoperiodic system described in the Japanese quail in which a significant rise in circulating $\mathrm{LH}$ levels in plasma is detected by the end of a single day of 20L:4D (Nicholls et al, 1983). The pattern of photoinduced LH secretion in buntings also resembles those described in a few other species (Follett et al, 1975; Wingfield et al, 1980), in that in the intact birds, after a significant rise on $d$ 2 plasma $\mathrm{LH}$ remained at a relatively constant level but in the castrates the concentration of $\mathrm{LH}$ in plasma rose consistently until d 7 (fig 1A). Such a highly responsive photoperiodic system in buntings could be advantageous to study the neuroendocrine processes involved in the induction of the seasonal reproductive responses.

Earlier results from the resonance experiments in buntings (Tewary and Kumar, 1981a) have been interpreted within the framework of the hypothesis that an endogenous circadian rhythm of sensitivity to photoperiodic induction strongly free-runs in darkness and that alternate (2nd, 4th, 6th and so on) light pulses in a 36-h cycle 
(ie $6 \mathrm{~L}: 30 \mathrm{D}$ or $8 \mathrm{~L}: 28 \mathrm{D}$ ) interact with $\Phi \mathrm{i}$, located in the middle of the subjective night, and thus induce gonadal recrudescence. The present results on the plasma $\mathrm{LH}$ response under $8 \mathrm{~L}: 28 \mathrm{D}$ (fig $3 \mathrm{~B}$ ) add weight to the above view and suggest that the photoperiodic time measurement system in the bunting involves a circadian rhythm of photosensitivity. Thus, the blackheaded bunting appears to be similar to some other photoperiodic species in which a strong positive effect of a resonating 36-h cycle has been demonstrated (Hammer, 1963; Turek, 1974; Kumar and Tewary, 1982). However, the Japanese quail, in which the photoperiodic clock is based on the circadian system, shows a weak response under a 36-h cycle containing a short photophase (6L:30D) (Follett et al, 1981) although the degree of induction can be improved by increasing the length of the photophase. The induction of a longday response in the quail under a 36-h cycle is directly related to the length of the photophase between 6-11 h (Follett et al, 1992). This raises the question of qualitative differences of the photoperiodic clocks among the different species of photoperiodic birds. One could argue that the degree of induction of a photoperiodic response in buntings under a 36-h cycle containing very short photophases (eg $1 L: 35 D$ of $3 L: 33 D)$ might be different from those exposed to $6 \mathrm{~L}: 30 \mathrm{D}$ or $8 \mathrm{~L}: 28 \mathrm{D}$. We intend to explore this hypothesis in our future experiments.

\section{ACKNOWLEDGMENTS}

The $L H$ radioimmunoassay $(R \mid A)$ was carried out at the AFRC Group on Photoperiodism and Reproduction, University of Bristol, UK. We are grateful to BK Follett for his suggestions and for providing RIA facilities. Financial assistance from the Council of Scientific and Industrial Research and the University Grants Commission of India is acknowledged.

\section{REFERENCES}

Davies DT, Goulden LP, Follett BK, Brown NL (1976) Testosterone feedback on luteinizing hormone (LH) secretion during a photoperiodically induced breeding cycle in Japanese quail. Gen Comp Endocrino/ 30, 477-486

Farner DS, Donham RS, Matt KS, Moore MC, Wingfield JC (1983) The nature of photorefractoriness. In: Avian Endocrinology: Environmental and Ecological Perspectives (Mikami S, Homma K, Wada M, eds) JSSP Tokyo/Springer-Verlag, Berlin, 145-166

Follett BK (1984) Birds. In: Marshall's Physiology of Reproduction (Lamming GE, eds) Churchill Livingstone, Edinburgh, 283-350

Follett BK, Scanes CG, Cunningham FJ (1972) $A$ radioimmunoassay for avian luteinuizing hormone. J Endocrinol 52, 359-378

Follet BK, Farner DS, Mattocks PWJr (1975) Luteinizing hormone in the plasma of whitecrowned sparrows (Zonotrichia leucophrys gambelii) during artificial photostimulation. Gen Comp Endocrinol 26, 126-134

Follett BK, Robinson JE, Simpson SM, Harlow CR (1981) Photoperiodic time measurement and gonadotropin secretion in quail. In: Biological Clocks in Seasonal Reproductive Cycles (Follett BK, Follett DE, eds) Scientechnica, Bristol, 185-202

Follet BK, Kumar V, Juss TS (1992) Circadian nature of the photoperiodic clock in Japanese quail. J Comp Physiol A 171, 533-540

Gibson WR, Follett BK, Gledhill B (1975) Plasma levels of luteinizing hormone in gonadectomized Japanese quail exposed to short or to long daylengths. J Endocrinol 64, 87-101

Hammer WM (1963) Diurnal rhythm and photoperiodism in testicular recrudescence of the house finch. Science 142, 1294-1295

Kumar V, Tewary PD (1982) Photoperiodic regulation of the gonadal recrudescence in common Indian rosefinch: dependence on circadian rhythms. J Exp Zool 223, 37-40

Mattocks PW Jr (1985) Absence of gonadalhormone feedback on luteinizing hormone in both photorefractory and photosensitivve white-crowned sparrows (Zonotrichia leucophrys gambelii). Gen Comp Endocrinol 60, 455-462 
Nicholls TJ, Follett BK, Robinson JE (1983) A photoperiodic response in gonadectomized Japanese quail exposed a single long day. $J$ Endocrinol 97, 121-126

Nichols TJ, Goldsmith AR, Dawson A (1988) Photorefractoriness in birds and comparison with mammals. Physiol Rev 68, 133-176

Sharp PJ, Moss R (1977) The effect of castration on plasma $\mathrm{LH}$ levels in photorefractory red grouse (Lagopus lagopus scotticus). Gen Comp Endocrinol 32, 289-293

Tewary PD, Kumar V (1981a) Circadian periodicity and the initiation of gonadal growth in the blackheaded bunting (Emberiza melanocephala). J Comp Physiol B 144, 201-203

Tewary PD, Kumar V (1981b) Effect of castration on photoperiodically induced weight gain in a migratory finch: blackheaded bunting Emberiza melanocephala. Indian J Exp Biol $19,469-471$

Tewary PD, Kumar V (1982) Photoperiodic responses of a subtropical migratory finch, the blackheaded bunting Emberiza melanocephala. Condor 84, 168-171
Turek FW (1974) Circadian rhythmicity and initiation of gonadal growth in sparrows. J Comp Physiol 92, 59-64

Wilson FE (1985) Androgen feedbackdependent and independent control of photoinduced $\mathrm{LH}$ secretion in male tree sparrows (Spizella arborea). J Endocrinol 105, 141-152

Wilson FE (1990a) The drive on luteinizing hormone secretion in castrated tree sparrows (Spizella arborea) exposed to short days is daylength independent. Gen Comp Endocrinol $77,484-488$

Wilson FE (1990b) On the recovery of photosensitivity in two passerine species, American tree sparrows (Spizella arborea) and Harris' sparrows (Zonotrichia querula). Gen Comp Endocrinol 79, 283-290

Wilson FE, Follett BK (1974) Plasma and pituitary luteinizing hormone in intact and castrated tree sparrow (Spizella arborea) during a photoinduced gonadal cycle. Gen Comp Endocrinol 23, 82-93

Wingfield JC, Follett BK, Matt KS, Farner DS (1980) Effect of daylength on plasma FSH and $\mathrm{LH}$ in castrated and intact white-crowned sparrows. Gen Comp Endocrinol 42, 464-470 